\title{
الصلابة النفسية وعلاقتها بتقدير الذات
}

\author{
! إعراد

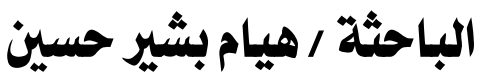

نغ

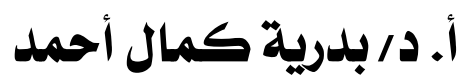

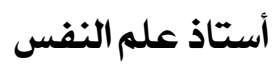

كليتتالآدابـ جامعت المنصورة

المجلت العلميت لكليت رياض الأطفال جامعت المنصورة

المجلد الثالث_ العدد الثالث

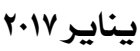




\section{الصلابة النفسية وعلاقتها بتقدير الذات}

أر هيام بشير حسين * - (2)

\section{أولاً: مقدمة الار اسة :}

بدأت الدراسات في مجال الضغوط النفـسية خــله الــسنو ات الماضــية

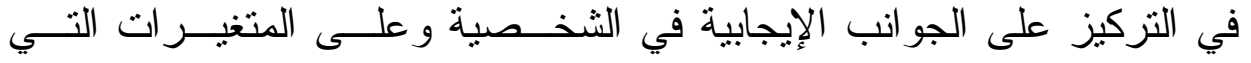

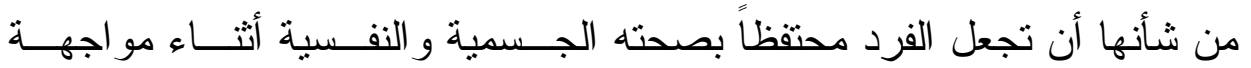
الضغوط ، وتمنل الصلابة النفسية إحدى هذه المتغيرات التي تساعد الفرد علـى

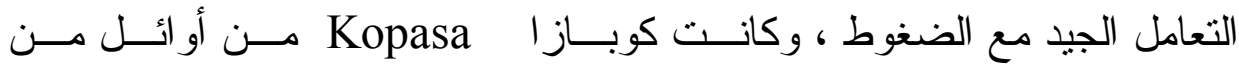

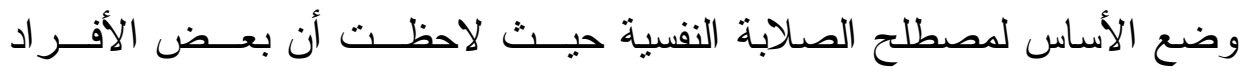

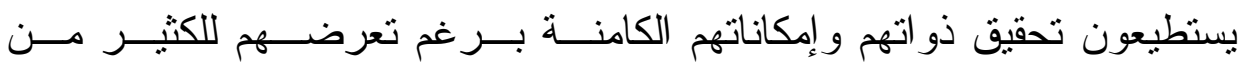
الإحباطات و الضغوط ، حيث أفترضت أن ذو الثخصية الصلبة يتمتـع بــناتلاث

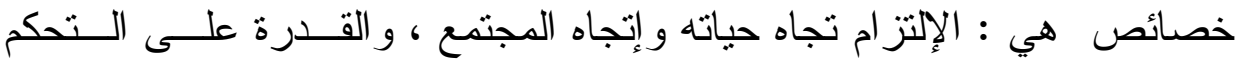

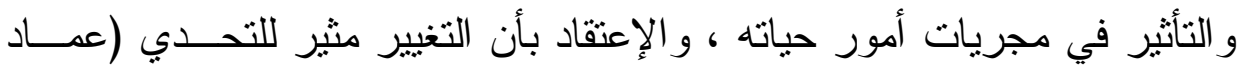
( ) مخيمر ،

كما أكدت كوباز ا على أن الصلابة النفـسية مفيــدة لمقاومــة الــضغوط و الإنهاك النفسي ، حيث أنها تُعدل من إدر الك الفرد للأحداث وتجعلها أقل أنثراً ،

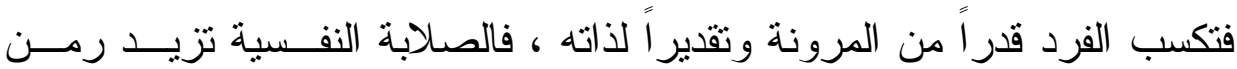
قدر ات الفرد على مو اجهة الضغوط المختلفة وزيادة مستوى تقدير الذات لديــهـ ، 
حيث يعتبر تقدير الذات من الأبعاد الهامة في حياة الأفــر اد حبــث يعبـر عـنـ

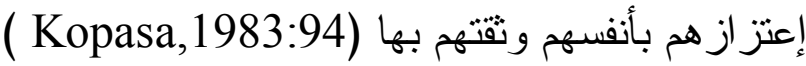

حيث يشير كوبر سميث 1967 Cooper Smith إلى تقدير الــات بأنسـه

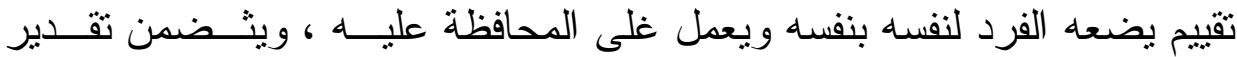

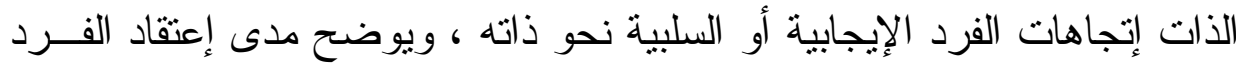
بأنه قادر وهام وناجح وكفه ، فتقدير الذات خبرة ينقلها الفرد إلــى الأخــرين

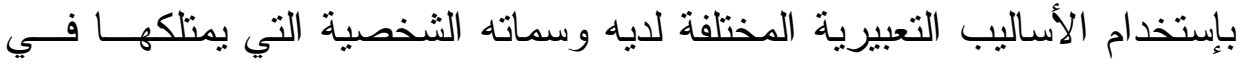

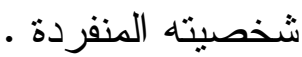

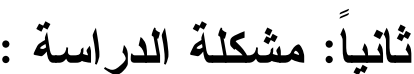

$$
\text { يمكن تحديد مشكلة الدراسة في الإجابة على التساؤل الأتي :- }
$$

س - هل توجد علاقة بين الصلابة النفسية بأبعادها وتقدير الذات لدى أعـضاء

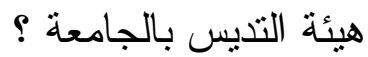

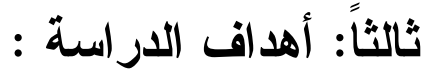

تهدف الدراسة الحالية إلى التعرف على العلاقة بين الــصلابة النفـسية

$$
\begin{aligned}
& \text { بأبعادها وتقدير الذات لاى أعضاء هيئة التدريس بالجامعة. }
\end{aligned}
$$

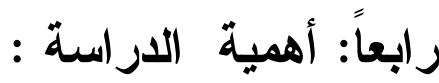

$$
\begin{aligned}
& \text { الأهمية النظرية : النالية }
\end{aligned}
$$

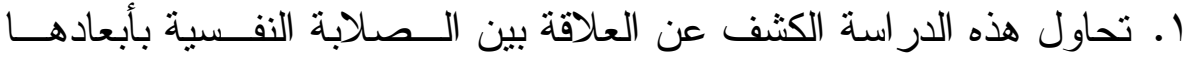

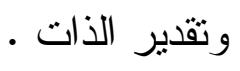

$$
\text { r. تركيز الدراسة على الجو انب الإيجابية في الثخصية . }
$$


r. إعطاء صورة عن مدى صلاحية الأدوات المستخدمة في هــذه الدر اســـة

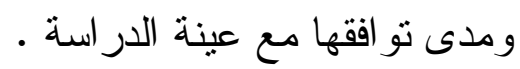

ء. إعطاء صورة و اضحة عن أعضاء هيئة التدريس بالجامعة التي تُعد عينة

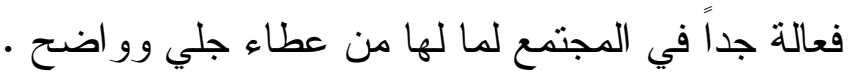
خامساً: مصطلحاث الدر اسة :

\section{ا 1 ـ الصلابة النفسية :}

تعرف الصلابة النفسية بأنها إحتفاظ الفرد بصحته النفسية و الجسدية علـىى

$$
\begin{aligned}
& \text { الرغم من تعرضه للظروف الضاغطة } \\
& \text { أ. أل الإلتز ام : }
\end{aligned}
$$

يمنتل القدرة على إدر الك الفرد لقيمه و أهدافه وتقدير إمكانياته لكــي يكــون لديه هدف يحققه وكذلك صنع القر ا رات التي تدعم التوازن و التز اكيب الداخليـــة

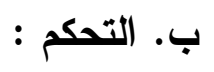

إعتقاد الفرد بالتحكم فيما يلقاه من أحــداث ، و أنـــهـ يتحمــل المـسؤولية

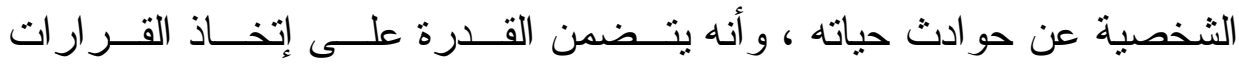
و الإختيار بين البدائل وتفسير الأحداث و المو اجهة الفعالة.

$$
\text { : التحدي }
$$

إعتقاد الشخص أن ما يطر أ من تغيير على جو انب حياته هو أمــر مثيــر وضروري للنمو أكثر من كونه تهديداً مما يساعده على المبــادرة و إسنتكـشاف هو 
البيئة ومعرفة المصادر النفسية والإجتماعية التي تـساعد الفردعلـى مواجهــة

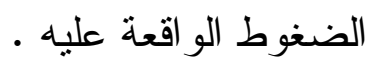

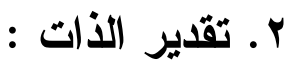
هو تقييم يضعه الفرد لنفسه بنفسه ويعمل على المحافظة عليه ، ويتـ إنمن

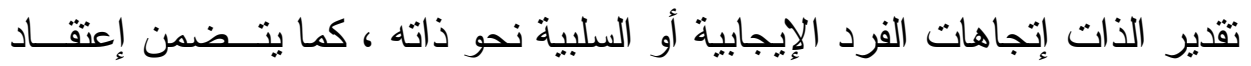

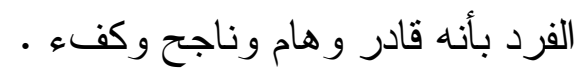
r. أعضاء هيئة التدريس بالجامعة : هم أثخاص مهنيين لديهم الحصيلة المعرفية و العلمية و المهارة و الثقة بالنفس

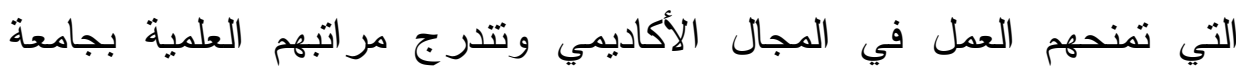

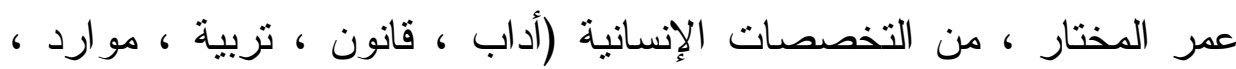

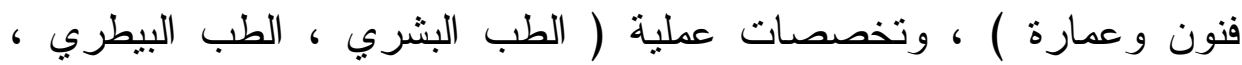
الصيدلة ، العلوم ، الهندسة ، الزر اعة ، الإقتصاد ) ، تراوحت أعمار هم مابين . (00-r.)

\section{سادساً: حدود الار (سة :} تتحدد الدراسة بالحدود التالية : المنهج المتبع في الدراسة : أنبعت الباحثة المنهج الوصفي الإرتبـاطي

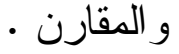

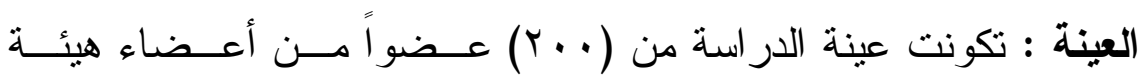

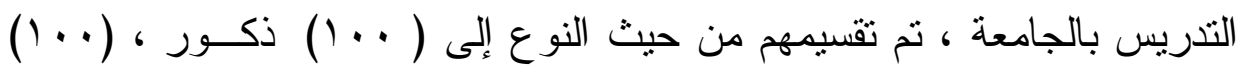
إناث 
العدود المكاتيــة : تم تطبيق أدوات الدراسة على أعضاء هيئة التــريس

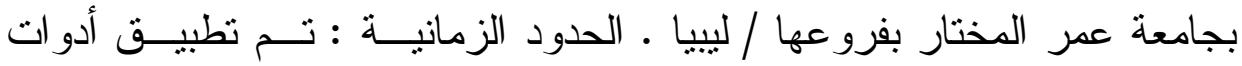

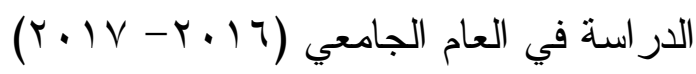

الأدوات : تتحدد الدر اسة بالأدوات المستخدمة فيهـــا لقـــاس متغير اتهــا الرئيسية و المتمتلة في مقياس الصلابة النفسية ( إعداد عماد مخيمر ) ، ومقياس

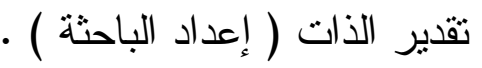

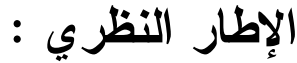
أولاً : الصلابة النفسية

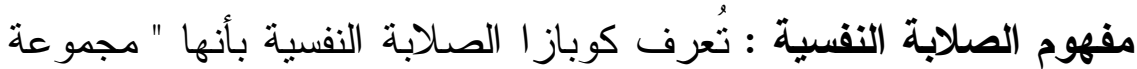

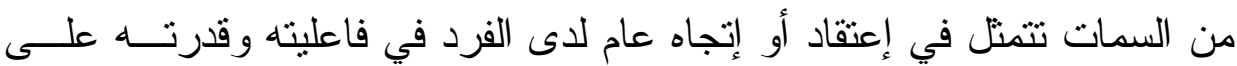

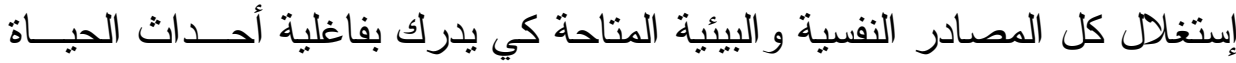

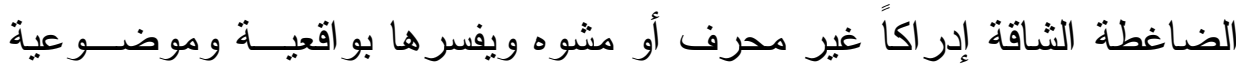
ومنطقية ، ويتعايش معها على نحو إيجابي وتتضمن ثلاثة أبعاد وهي " الإلتز ام،

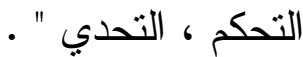

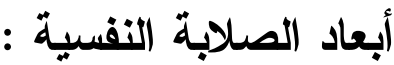

الإلتزام : يعتبر مكون الإلتز ام من أكثر مكونات الصلابة النفسية إرتباطاً

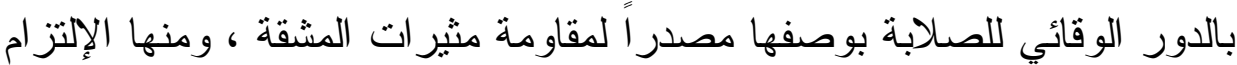

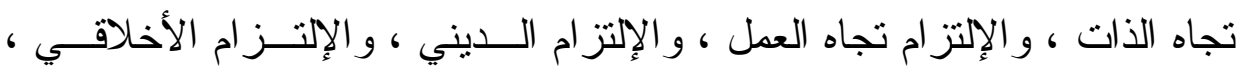

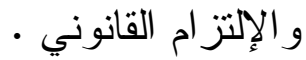

التحكم : هو تصور الفرد أن الأحداث وتجارب الحياة يمكن التحكم فيهــا وتوقعها ، و أنها تمنل نتيجة أعماله ، ويتضمن أربع صور من التهور التحم هي القدرة 
على إتخاذ القرارات و الإختيار بين البدائل ، التحكم المعرفــي( المعلومـاتي ) ، التحكم السلوكي ، التحكم الإسترجاعي .

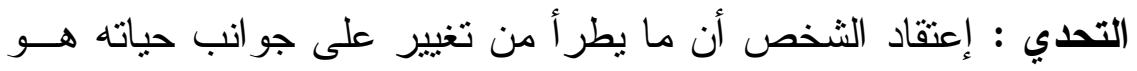

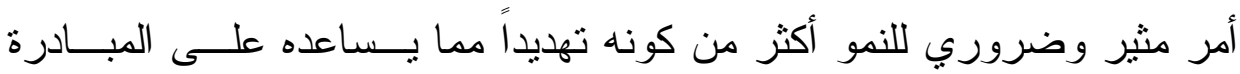

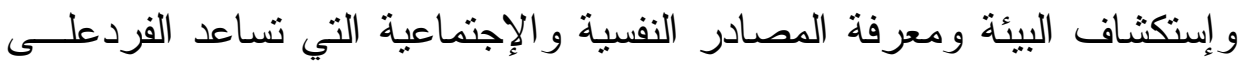
مو اجهة الضغوط الو اقعة عليه ـ خصائص الصلابة النفسية :

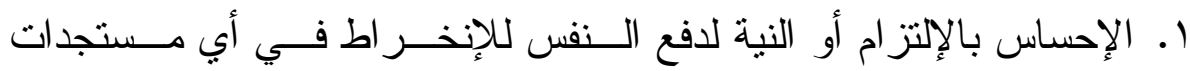
تو اجه8م r. الإيمان ( الإعتقاد ) بالسيطرة و الإحساس بأن الثخص نفسه هو سبياً لأي

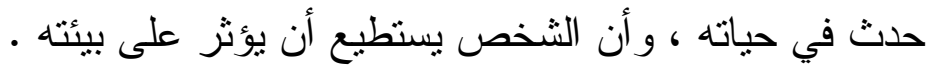

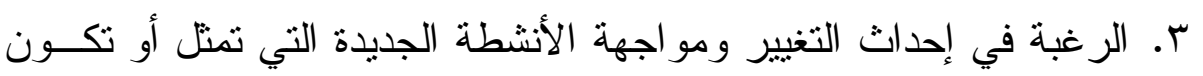
بمثابة فرص للنماء و التطوير •

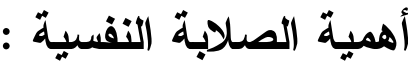

أن الصلابة النفسية مُركب مهم من مركبات و الثخصية التي تقي الإنسان

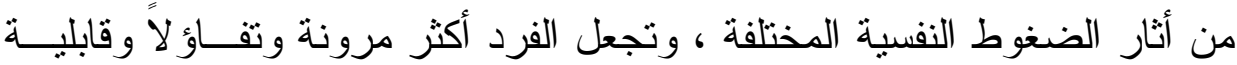
للتغلب على مشاكله الضاغطة ، كما وتعمل الصلابة النفسية كعامل حماية مـن النان الأمر اض الجسدية و الإضطر ابات النفسية ، كما تعمل الصلابة ومكوناتها كمتغير

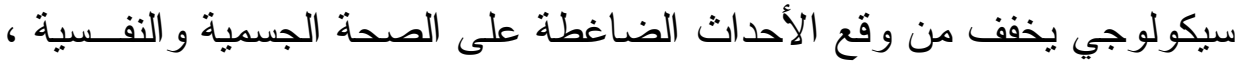
فالأفر اد الأكثر صلابة يتعرضون للضغوط و لا يمرضون (عماد مخيمر، 1997 . (rVT: 
تعتبر در اسة تقدير الذات من الموضوعات المهمة في البحــوث النفـسية و الثخصية ، فنحن نعيش في عصر محفوف بتغير ات سياسية و إقتصادية وثقافية لها تأثثر ها المباشر على الكائن البشري . فقد عرف كوبر سميث تقدير الذات بأنها تقييم يضعه الفرد لنفـسه بنفـسه ويعمل على المحافظة عليه ويتضمن تقديير الذات إتجاهات الفــرد الإيجابيــة أو

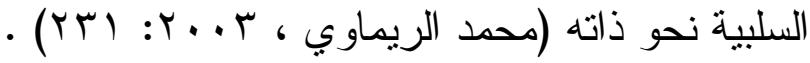
مستويات تقدير الذات : ا ـ المستوى المرتفع ( العالي ) لتقدير الأت . يرى هامشيك Hamachek أن الأشخاص الذين لديهم تقدير ذات مرتفـع يعتقدون أنهم ذوي قيمة و أهمية و أنهم جديرون بالإحتر ام و التقدير ، كمـــا أنهــ

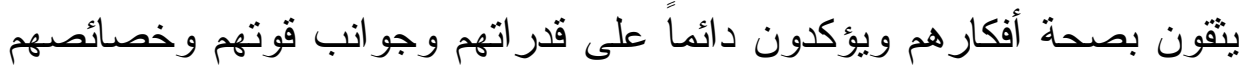

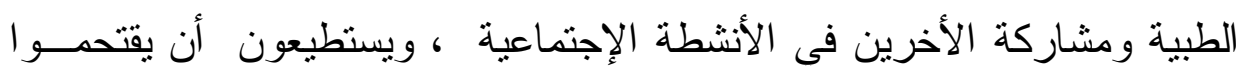
المو اقف الجديدة ولديهم حب إستطلاع الهن r. المستوى المنخفض ( المتدني ) لتقدير الذات.

أن الثخص الذي لديه مستوى متذني لتقدير الذات يمكن أن نصنفه بأنــــ ذلك الثخص الي يفتقر إلى الثقة في قدر اته ، وهو الذي لا يستطيع حل مشاكله،

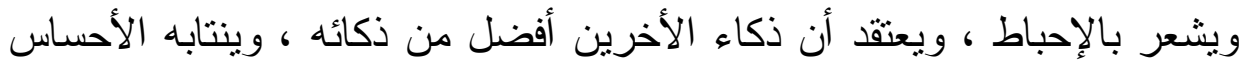
بالعجز و القلق نحو التعامل مع الأخرين ، كما يُبدي عدم رضاه عن مظهره العام (محمد الثناوي ، 1 +. ب: 0ب 1) . 


\section{مكونات تقدير الذات :}

تقدير الذات له مكونان أساسيان :

الكفاءة الذاتية : معناها تـتع المرء بالثقة بالنفس و إيمانه بأنه قادر غلـى

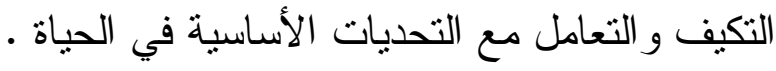

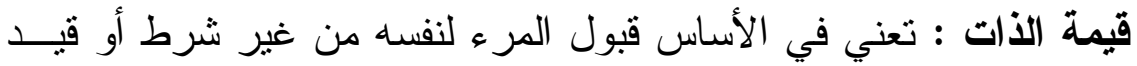

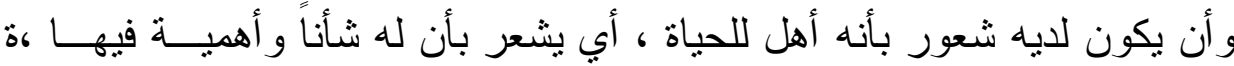

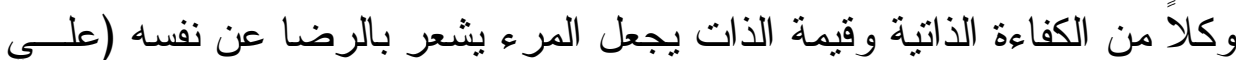

$$
\begin{aligned}
& \text { عسكر ، 0. . r: 70) . } \\
& \text { أهمية تقدير الذات: }
\end{aligned}
$$

يعتبر تقدير الذات أحد الأبعاد الهامة للثخصية ، بل ويعتبرها العلماء من

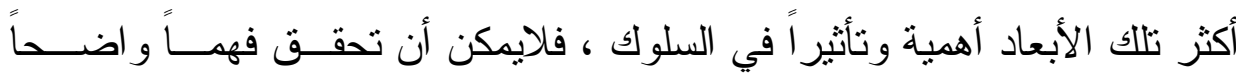

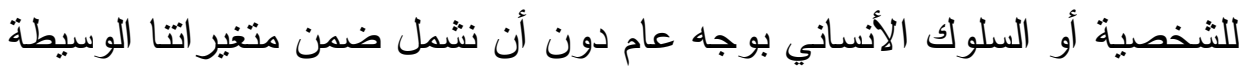
مفهوم تقدير الذات ، حيث يرى البورت (Albort ) أن تقدير الذات يدخل فيـي

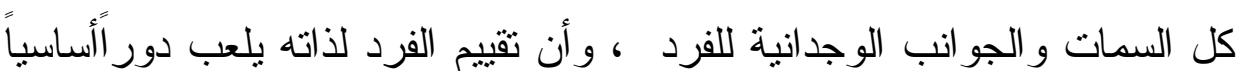

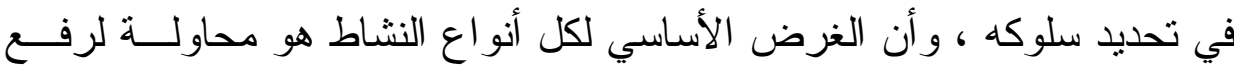
تقدير الذات ، كما يؤثر تقدير الذات في تحديد أهداف و إتجاهـات و إســتجابات

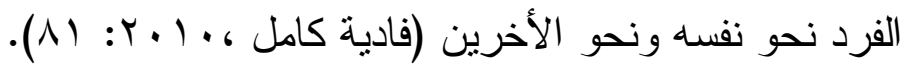

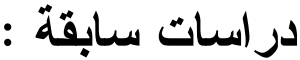

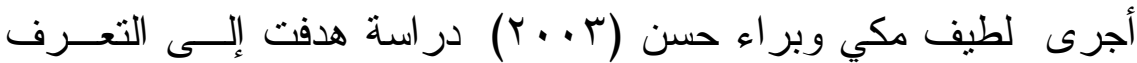

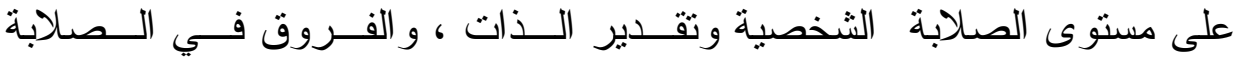
الثخصية وتقدير الذات لدى التدريسيين بالجامعة تبعاً لمتغير النوع ، كما تهدف 
الدر اسة إلى التعرف على العلاقة بين الصابلة النفسية وتقدير الــذات هوذلــلك

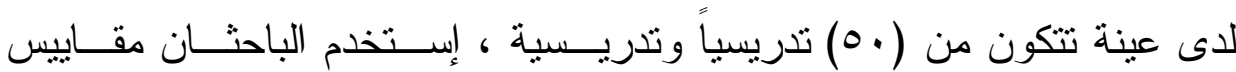
الصلابة النفسية وتقدير الذات .

أوضحت نتائج الدر اسة أنه توجد علاقة إرتباطية موجبة بــين الــصلابة

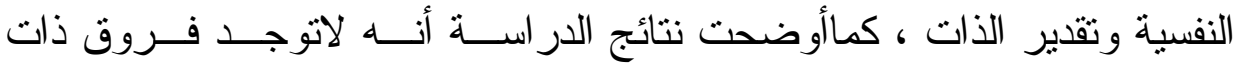
دلالة إحصائية في الصلابة النفسية وفقــاً لمتغيــر النــوع لــدى التـربـسيين

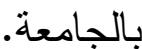

كما أجرت منيرة بنت سالم (10 ب ب) در اسة هذفت إلـى التعــرف علــى مستوى الصلابة النفسية بأبعادها الثالثة ( الإلتز ام ، التحكم ، التحدي ) وتقـدير الذات و الرضـا الوظيفي ، و التعرف على العلاقة بين الصلابة النفـسية وتقــدير الذات و الرضا الوظيفي وذلك لدى عينة تكونت من (ع ه) مفحوصة ـ إستخدمت الباحثة مقاييس الصلابة النفسية وتقدير الذات و الرضا الوظيفي •

أوضحت نتائج الدر اسة إرتفاع مستوى الصلابة النفسية بأبعادهــــا الثلاتـــة

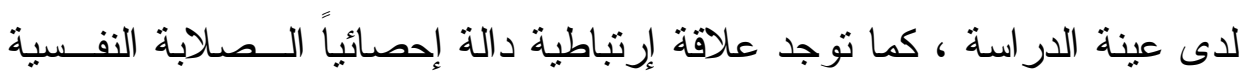
وكل من تقدير الذات و الرضا الوظيفي •

و أجرى (Ghalyanee,2016) در اسة هدفت إلى التعرف علــى العلاقــة

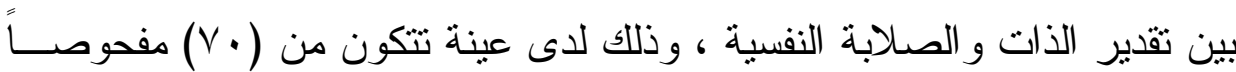

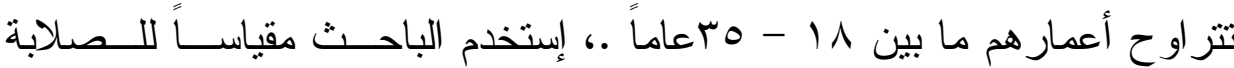

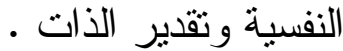

أوضحت نتائج الدراسة أنه توجد علاقة موجبة بين تقدير الذات و الصلابة

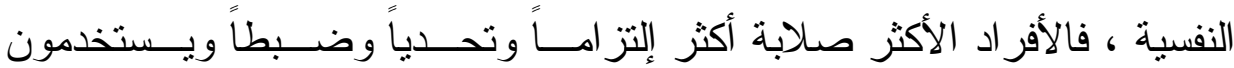
إسر اتيجيات التغلب على المشكلة ، ويدركون أنفسهم بأنهم يتمتعون بفعالية ذاتيـــة ولئة 
عالية حيث حيث لا يميلون إلى العجز المتعلم في مواجهة الظروف الــصعبة، و كما أن الصلابة النفسية تعزز لاى الأفر اد قيمة الذات وتقدير الذات. فروض الدراسة :

بعد إستقر اء الأطر النظرية و الدر اسـات السابقة يمكـن صــــاغة فــروض

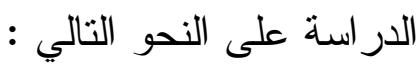
توجد علاقة ذات دلالة إحصائية بين الصلابة النفـسية بأبعادهـــا وتقــدير الذات لاى عينة من أعضاء هيئة التذريس بالجامعة. منهج الدر اسة و إجراعاتها : تتبع الدر اسة الحالية المنهج الوصفي الإرتباطي و المقــارن ، حيــث يــتم

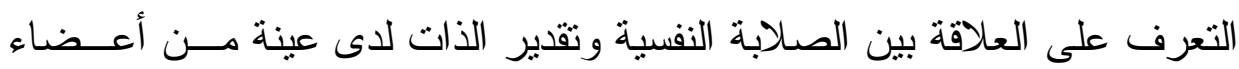
هيئة التدريس بالجامعة .

\section{مجتمع الدراسة : مجن}

يتكون مجتمع الدر اسة من جميع أعضاء هيئة التــدريس بجامعــة عمــر

المختار بفروعها " البيضاء ، القبة ، درنة " من الجنسين ، وقد بلغ عدد أعضاء

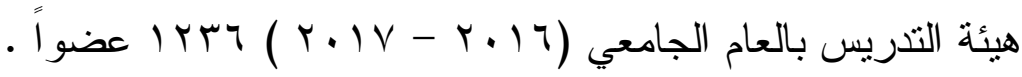
عينة الدر (سلة :

تكونت عينة الدر اسة الميدانية من . . عضواً ، . . . 1 من التخصـصـات

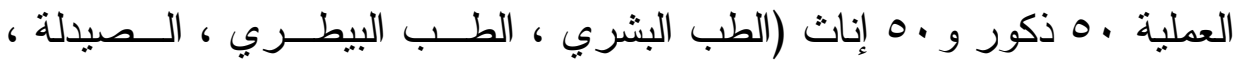

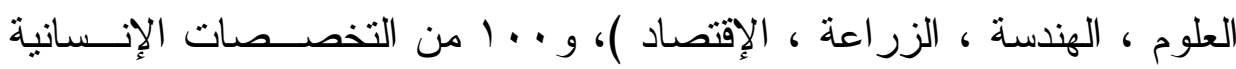

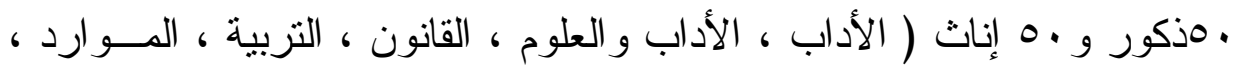
الفنون و العمارة ، اللغات ) ) 


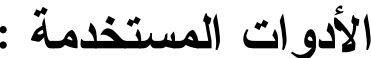

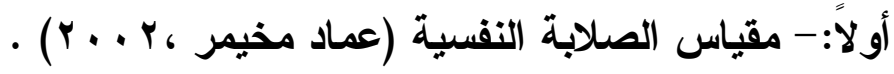

قامت الباحثة بالتحقق من الكفاءة السيكومترية لمقياس الــصلابة النفسية وذلك بعدة طرق للتحقق من صدق المقياس وثباته ، وذللك على عينة إستطلاعبة بالية من أعضاء هيئة التنريس بالجامعة. ثانياً :- مقياس تقدير الذات (إعداد الباحثة ). قامت الباحثة بحساب الكفاءة السيكومترية لمقياس تقدير الذات وذلك بعسدة طرق للتحقق من صدق المقياس وثباته ، وذللك علــى عينـــة إســنطلاعية مــن أعضاء هيئة التدريس بالجامعة . عينة الار اسة الميدانية : مئة

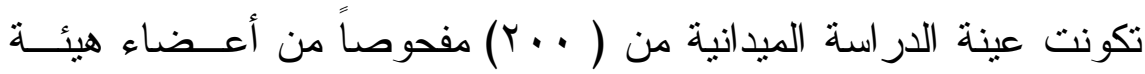

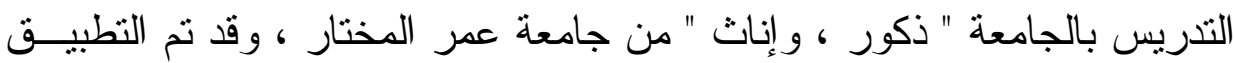

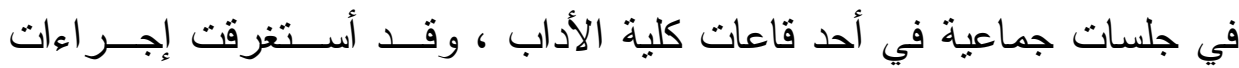

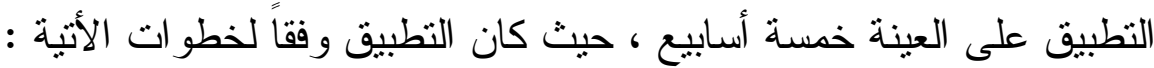
ا ـ قامت الباحثة بتعريف نفسها لعينة الدر اسة .

r. أوضحت الباحثة للمفحوصين أن البيانات التي تحصل عليها لا تستخدم إلا

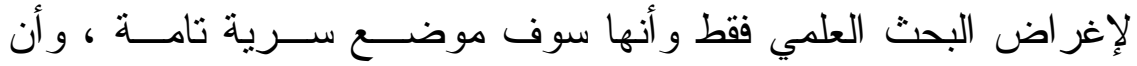

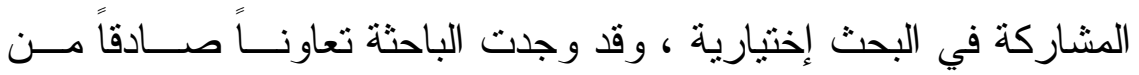

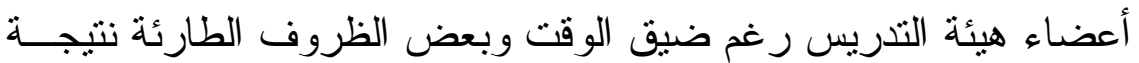
للحرب في بعض مناطق ليييا . 
الأساليب الإحصائية المستخدمة في الاراسة :

مُعاملات إرتباط بيرسون Person cofficient، وســبيرمان - بـــر اون

Cronbach Alpha ومعامل ألفا كرونباخ Sperman-Brown

T.Test أ- إختبار "ت

ج- تحليل الإنحدار المتعدد Stepwise Multiple Regression

وقد إستخدمت الباحثنة الحزمة الإحــصائية للعلــوم الإجتماعيــة لإجر اء المُعاملات الإحصائية لكل بيانات الدر اسة . لإنة

عرض نتائج الدر اسة وتفسير ها ومناقتشتها :

الفرض الأول : ينص على أنه " توجد علاقة إحصائية دالة بـين الــصلابة

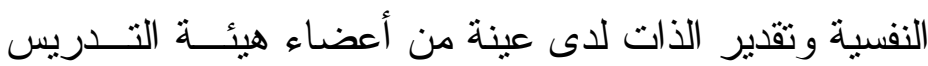

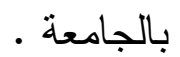

وللتحقق من صحة الفرض قامت الباحثة بحساب قيمة مُعامل الإرتباط بين

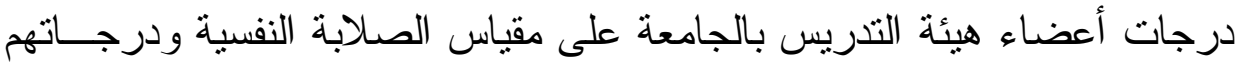

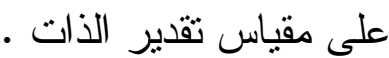

ويوضح الجدول قيمة مُعامل الإرتباط بين درجات أعضاء هيئة التـدريس

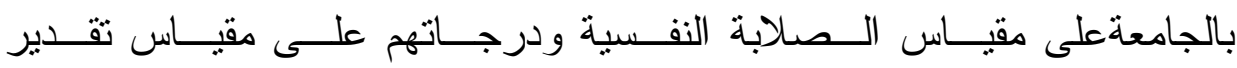

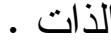




\section{جدول}

قيم مُعامل الإرتباط بين درجات أعضاء هيئة التدريس بالجامعة على مقياس الصلابة النفسية ودرجاتهر على مقياس تقدير الذات ومستوى الالالة

\begin{tabular}{|c|c|c|}
\hline قيمة معامل الإرتباط & ن & المتفيرات \\
\hline$* *,, \vee 90$ & $r \ldots$ & تقدير الذابة النفسية \\
\hline
\end{tabular}

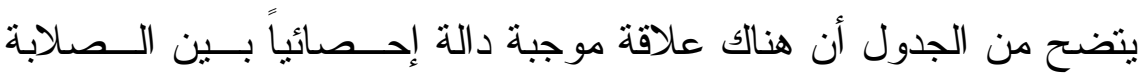

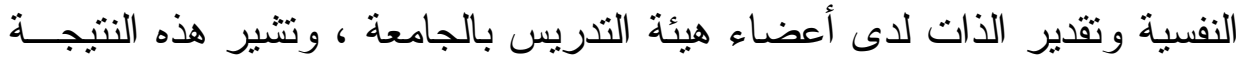
إلى تحقق صحة الفرض.

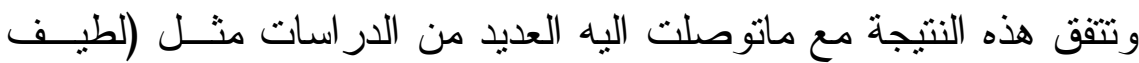

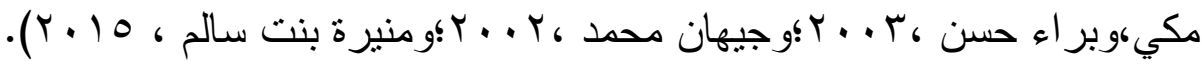
التوصيات و البحوث المقترحة :

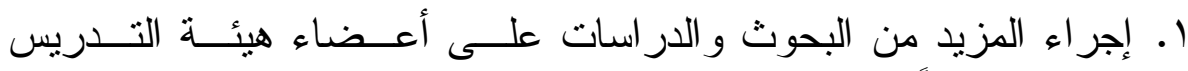
بالجامعة نظر أ لإهمية هذه الفئة . ل

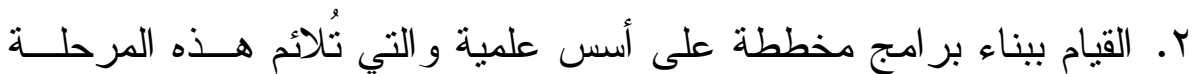
لإساتذة الجامعة وتطوير تقدير الذات لديهر علئ

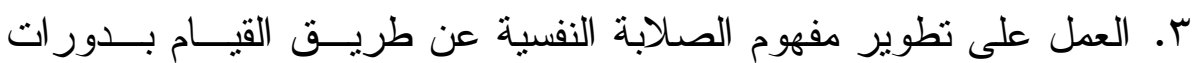
تربوية ونفسية تزيد من خبرة أعضاء هيئة التدريس بالجامعة لفية

$$
\text { البحوث المقترحة : }
$$

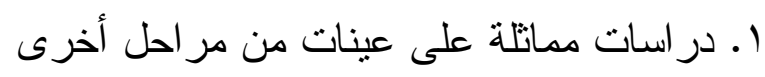

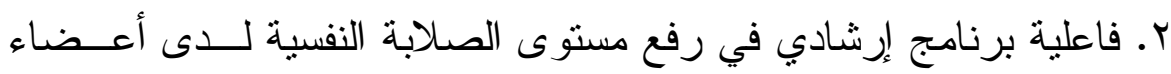

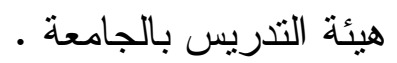




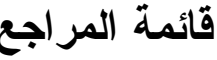

\section{أولاً : المر اجع العربية :}

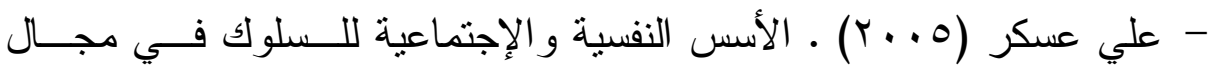
العمل ـ الكويت ـ دار الكتاب الحديث للنشر و التوزيع ، طا لإيل

- عماد مخيمر (997 (99). إدر الك القبول / الرفض الو الدي و علاقته بالــصلابة

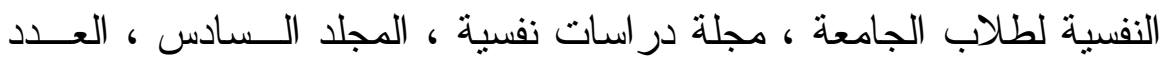

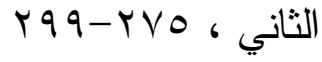

- عماد مخيمر (99V ( 9 ) ـ الصدابة النفسية و المساندة الإجتماعيــة متغيـر ات وسيطة في العلاقة بين الضغوط و أتعر اض الإكنئاب لدى الثباب الجامعي ،

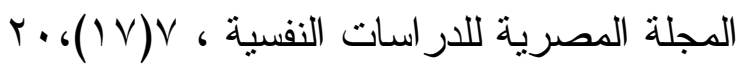

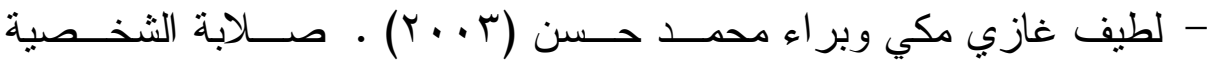
و علاقتها بتقدير الذات لدى التدريسيين في الجامعة ، جامعة بغداد : مجلــة البحوث التزبوية و النفسية .

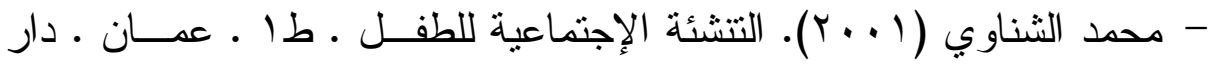
• صفاء للنشر

- منيرة بنت سالم (0 ( ب). الصلابة النفسية وعلاقتها بتقدير الذات و الرضـــا الوظيفي لاى السجانات ، أطروحة دكتور اة ، جامعة نايف العربية للعلــوم الأمنية ، كلية العلوم الإجتماعية و الإدارية. 


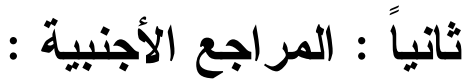

- Kobasa,S. \& Pucceti , M. (1983): " Personality and Social reources in stress resisance, Journal of Personality and Social Psychology, Vol . 45, No4,.

- Ghalyanee , Bahareh (2016). Relatienship Between Sey Esteem and Psychological Hardiness in Adlocanto : A Relation Derigm .the international of fmdian Psyhology.Not .3. no - 10 Pp. $116-122$. 